\title{
CIRCULAR ECONOMY AND NEW WAYS OF DOING BUSINESS IN THE TOURISM SECTOR
}

\section{GiUlio Pattanaro, ${ }^{1}$ VinCEnZo Gente ${ }^{2}$}

\begin{abstract}
'Independent Reseacher, ITALY
e-mail: giuliopattanaro@gmail.com

${ }^{2}$ Environmental Engineer, ITALY

e-mail: vincenzo.gente@ingpec.eu

RECEIVED

2 November 2015

ACCEPTED

10 February 2017

JEL

CLASSIFICATION

Q30, Q53, Q56, Z32

KEYWORDS

circular economy, tourism development, business models, sustainability

ABSTRACT

In alternative to the current linear economic model of extraction use and disposal, the emerging concept of circular economy stresses the importance of maintaining the value of products, materials and resources inside the economy thus reducing waste generation and improving sustainability. The opportunity of switching to a circular model of production and consumption is currently explored in different economic sectors, including tourism.

This paper investigates the transition towards circular economy in the area of tourism. After a review of the most relevant literature on the subject, some concrete examples of circular economy applied to tourism destinations and companies are examined and compared. The implications of the transition towards circular economy in the area of tourism, mainly in terms of new business models and practices, are then analysed and discussed. Further research on the topic and the investigation of additional case studies is finally suggested.
\end{abstract}

\section{Introduction}

Global demand for inclusive well-being is putting increasing pressure on the environment. At the same time, today's world is facing resource constraints, linked with price volatility and market instability. These economic and environmental issues represent a limit to the current linear extraction-use-disposal model of production and consumption, and are paving the way to new circular economy models, where "the value of products, materials and 
resources is maintained in the economy for as long as possible, and the generation of waste minimised" (EC, 2015, p. 2). These models are seen more and more as fundamental for the development of a sustainable, low carbon, resource efficient and competitive economy, in different sectors, including tourism.

The purpose of this paper is to investigate the challenges linked to the transition towards circular economy in the area of tourism. A review of the most relevant literature on the subject will be followed by the illustration of some practical experiences of circular economy, at the level of both destinations and individual tourism players.

\section{The notion of circular economy}

The concept of circular economy has being attracting the interest of both the scientific community and policy makers, with a number per year of scientific papers on the subject which more than doubled from 2010 to 2015 (Lieder, Rashid, 2016) and a dedicated action plan for circular economy adopted by the European Commission (2015).

The concept of circular economy is not completely new and is linked to sustainable development. Since the publication, in 1987, of the United Nations' Our Common Future report (WCED, 1987), it is generally accepted that sustainable development needs a convergence between economic development, social equity, and environmental protection. Science-based perspectives - e.g., Life Cycle Assessment (LCA), cradle-to-cradle, or, in a more general interdisciplinary framework, industrial ecology - were explored and developed with the purpose of finding ways to assess and reduce the negative effects on the environment of industrial activities and products (Genovese, Acquaye, Figueroa, Koh, 2017).

The circular economy framework moves from a merely environmental approach towards more comprehensive business models so as to boost economic growth and competitiveness and attract companies and investors (EC, 2015; Ellen MacArthur Foundation, 2015). The final aim is to close material loops and extend the lifespan of materials through longer use, increased use of secondary raw materials, and material substitution (OECD, 2015). Products are designed to be used more efficiently, and to be returned back to the producer at the end of their life cycle for further use (through update or upgrade) or for being dismantled and recycled. End-users buy products for the functions that they can deliver and industries provide services and products that end-users can co-design. New business models are then developed and the responsibility of the end-of-life management is shifted from the end-user to the producer, who is encouraged to adopt eco-design practices.

The circular economy framework calls for an increased collaboration not only between the producer and the end-user but also between the private and public sector. The public sector in particular can promote more sustainable consumption behaviours, providing the infrastructures which are needed and facilitating investments, for instance by embedding circular economy in public procurement.

\section{A husiness model for the circular economy}

Shifting from a linear to a circular economic model implies several factors: the design and development of new products and services, the full appreciation of the value of waste as a resource, the re-thinking of traditional logistical networks and the commitment of policy makers to establishing a supportive framework. The transition to circular economy has major implications for business players, who have to reconsider the way they have been operating so far. Some upcoming models like the collaborative economy or the sharing economy - with the consumer who cocreates and shares products and services through online platforms such us Uber or Airbnb - are already directly or 
indirectly associated to the shift towards the circular economy (Basu, 2001; Cusumano, 2015; WEF, 2014; Hamari, Sjöklint, Ukkonen, 2015; Kenney, Zysman, 2015).

After an extensive literature review, and inspired by the work on business models generation carried out by Osterwalder and Pigneur (2010), Lewandowski (2016) identifies the following eleven elements as the building blocks of a circular economy business model:

- value proposition, which also includes the transformation of products into services,

- customer segments, i.e. the capability to meet the demands of all type of customers,

- channels, i.e. effectively communicating with customers also through digitalisation,

- customer relationships, i.e. production on demand and social-marketing,

- revenue streams, which include also less-traditional payment for usage,

- key resources, with a focus on better-performing materials,

- key activities, which also include better process control and improved design,

- key partnerships with all the actors along the value chain,

- cost structure, which has to consider also the incentives offered to customers,

- take-back system to encourage return and reuse,

- adoption factors, internal (e.g. corporate culture) or external (e.g. socio-economic issues).

\section{Tourism and circular economy}

A review of some academic insights on the transition towards circular economy in tourism will be followed by the illustration of some examples of destinations and individual tourism companies which have been implementing the principles of circular economy. Academic and non-academic web search engines but also some more specific databases like The Guardian's influential Circular Economy Hub (The Guardian, 2016) were consulted to feed this section.

\section{Some inputs from literature}

From a search performed on Google Scholar, ScienceDirect and Scopus it emerges that the very few academic papers on tourism and circular economy are almost exclusively authored by Chinese scholars. As Su, Heshmati, Geng and Yu (2013) explain, in China circular economy is seen as a new development model leading to a more sustainable economy. Its implementation has been strongly supported by the $12^{\text {th }}$ five-year plan (2011-2015), with pilot initiatives launched in cities like Beijing, Shanghai, Tianjin or Dalian. These initiatives address also the longterm sustainability of tourism, an industry whose rapid development has put a lot of pressure on natural resources, with negative implications on the development and image of destinations (Tang, 2015; Wu, Dong, Cheng, 2010).

Even if circular economy indicators tend to be focused on resource consumption and waste management (Geng, Zhu, Doberstein, Fujita, 2009), in China as well the scope of circular economy has been gradually expanded. For instance, Wu, Dong and Cheng (2010) propose a quite complex tourism development model in which traditional components like waste management and resource efficiency are combined with socio-economic aspects like production and consumption patterns.

Effective implementation of a more extensive notion of circular economy calls for a wide set of measures, which include the support for the development of greener technologies, a reinforced cooperation among local 
actors, and the use of public investments to raise awareness and promote sustainable production and consumption patterns (Fan, 2008; Su, Heshmati, Geng, Yu, 2013; Wu, Dong, Cheng, 2010).

\section{Circular economy at the level of destinations}

As a result of a search performed mainly on Google and on The Guardian's influential Circular Economy Hub (The Guardian, 2016), a limited number of destinations explicitly mentioning the circular economy was found: two cities (Copenhagen and Rotterdam) and two regions (Pomorskie and Venlo) in Europe, and four cities (Beijing, Dailan, Shanghai, and Tianjin) and one region (Mount Emei Scenic Area) in China. In most of these destinations, tourism development is part of a more general local plan to encourage the transition towards circular economy. For instance, in the case of the Netherlands - a country with a strong interest and commitment to supporting the transition towards circular economy (e.g., see TNCH, 2016), the tourism operators of the area of Venlo have been working together with other businesses (e.g., agro-food companies) and the local community as part of an overall project to create an attractive living and working environment (Innovation Seeds, 2006; Venlo Green Park, 2016).

More focus on tourism can be found in the development model adopted in the Mount Emei Scenic Area - a UNESCO World Heritage Site located in the Sichuan Province - which includes initiatives like green public procurement, dedicated trainings for tourism staff and commercialisation of eco-friendly tourism packages (Zhang, Xiao, 2015).

\section{Circular economy at the level of single tourism companies}

Following a search performed in Google and within The Guardian's Circular Economy Hub (The Guardian, 2016), only one example of company which has been already applying the circular economy principles in its daily business could be found. It is the case of a biogas facility installed at Disney World Florida for the conversion of organic waste into energy (Gunther, 2014).

The web also reports of other potential circular economy -related business opportunities, like, for example, the possibility to recycle food waste from cruise companies and use it as feed in aquaculture (Strazza, Magrassi, Gallo, Del Borghi, 2015). Circular economy opportunities for tourism companies are frequently associated with the collaborative or sharing economy, and with successful business stories like Airbnb (Lazy, 2014; WEF, 2014).

\section{Critical factors to implement circular economy in the field of tourism}

Shifting towards the circular economy in the field of tourism requires the following elements:

- a broader perspective, which looks at environmental but also socio-economic issues,

- the involvement of all the players: e.g., the same as in the case of more "traditional" products, the tourist should be able to co-design her/his experience,

- a cross-sector approach, with different sectors (e.g., tourism, agro-food, mobility) which need to cooperate in order to optimise resources, materials, and value,

- new business models and new revenue streams (e.g., renting instead of selling).

At least two managerial issues appear to be still open. First, the notion of circular economy emerges as quite of a niche one, with no example of tourism operators making use of it for marketing and promotional purposes. Concepts like sustainable tourism or eco-tourism appear to be more appealing, with far more examples available on the web. The second open issue is represented by the definition of adequate performance indicators, with the 
current ones which tend to be limited to environment-related measures (e.g., recycling rates or water efficiency) and which therefore do not take full account of that broader scope of circular economy.

\section{An early stage of development}

The present research work shows that the academic debate on circular economy and tourism is quite limited and very few are the practical examples of destinations and individual operators which are endorsing the principles of circular economy.

Some methodological choices may contribute to explaining this situation. The search performed for the purpose of this paper was carried out only through some major online search engines. A larger investigation, accompanied by a hands-on analysis of the different cases, could have provided additional examples and further insights on the specificities of each single case. In addition to this, no search was performed in order to identify potential situations in which - also due to a limited marketing appeal of the notion of circular economy which was mentioned before - other terminologies have been used to qualify, promote and certify activities which would perfectly fit the circular economy.

Despite these methodological limitations, it emerges quite clearly that the concept itself of circular economy should be further and/or better defined and promoted. Circular economy goes far beyond recycling and reuse of materials and resources: it is about new business models, new production and consumption patterns, and new partnership agreements between different players and industries. However, also in the few examples mentioned in the previous paragraphs, most emphasis is still put on waste management and energy efficiency. Academics should further work in this direction, also to avoid misunderstanding and overlapping with some related and better known concepts like sustainable development or resource efficiency. Links should also be established with other fields of research - e.g. network analysis, multi-stakeholder governance, collaboration and partnerships - whose inputs and findings may be relevant for the circular economy as well.

\section{Conclusions}

With its need to find a balance between economic benefits and environmental protection, tourism qualifies as a very interesting area where to test and implement the circular economy. A successful transition towards the circular economy, in tourism like in any other business sector, requires the adoption of a systemic approach, which looks at environmental but also socio-economic issues and implications. This implies the involvement and participation of the largest possible number of players, so as to optimise resources, materials and value. Furthermore, new business models, which can transform traditional revenue streams and ownership arrangements, are needed to accompany this transition.

Both academics and practitioners (tourism decision-makers included) should better define and promote the notion of circular economy. Some open issues, like, for example, the need for indicators which take full account of its systemic nature, are to be better explored. This is why further research on the topic and the analysis of additional case studies, with contributions from all business sectors, is suggested.

\section{References}

Basu, R. (2001). New criteria of performance management. Measuring Business Excellence, 5 (4), 7-1.

Cusumano, M.A. (2015). How Traditional Firms Must Compete in the Sharing Economy. Communications of the ACM, 58 (1), 32-34. 
Ellen MacArthur Foundation (2015). Delivering the Circular Economy a Toolkit for Policymakers. Cowes: Ellen MacArthur Foundation. European Commission (EC) (2015). Closing the loop - An EU action plan for the Circular Economy. COM (2015) 614.

Fan, Y. (2008). Research on the Development of Tourism Circular Economy in Henan Province. Proceedings of International Conference on Industry Cluster Development and Management, 550-553.

Geng, Y., Zhu, Q., Doberstein, B. \& Fujita, T. (2009). Implementing China's circular economy concept at the regional level: A review of progress in Dalian, China. Waste Management, 29, 996-1002.

Genovese, A., Acquaye, A.A., Figueroa, A. \& Koh, S.L. (2017). Sustainable supply chain management and the transition towards a circular economy: Evidence and some applications. Omega, 26, 344-357.

Gunther, M. (2014). Disney World's biogas facility: a model for converting food waste into energy. The Guardian sustainable business, 17 October. Available at: http://the.guardian.com (27.07.2016).

Hamari, J., Sjöklint, M. \& Ukkonen, A. (2015). The sharing economy: Why people participate in collaborative consumption. Journal of the Association for Information Science and Technology, 1-13.

Kenney, M. \& Zysman, J. (2015). Choosing a future in the platform economy: the implications and consequences of digital platforms. Kauffman Foundation New Entrepreneurial Growth Conference - Discussion papers. Available at: http://www.brie.berkeley.edu (20.07.2016).

Lazy, P. (2015). The Circular Economy. Great idea but can it work? Forbes, 20 January. Available at: http://www.forbes.com (28.07.2016).

Lewandowski, M. (2016). Designing the Business Models for Circular Economy - Towards the Conceptual Framework. Sustainability, 8 (1), 1-28.

Lieder, M. \& Rashid, A. (2016). Towards circular economy implementation: a comprehensive review in context of manufacturing industry. Journal of Cleaner Production, 115, 36-51.

Organisation for Economic Co-operation and Development (OECD) (2015). Material Resources, Productivity and the Environment. Paris: OECD Publishing.

Osterwalder, A. \& Pigneur, Y. (2010). Business model generation: a handbook for visionaries, game changers, and challengers. Hoboken: John Wiley \& Sons.

Strazza, C., Magrassi, F., Gallo, M. \& Del Borghi, A. (2015). Life Cycle Assessment from food to food: A case study of circular economy from cruise ships to aquaculture. Sustainable Production and Consumption, 2, 40-51.

Su, B., Heshmati, A., Geng, Y. \& Yu, X. (2013). A review of the circular economy in China: moving from rethoric to implementation. Journal of Cleaner Production, 42, 215-227.

Tang, Z. (2015). An integrated approach to evaluating the coupling coordination between tourism and the environment. Tourism Management, 46, 11-19.

The Guardian (2016). Circular Economy Hub. Available at: http://the.guardian.com (1.11.2016).

The Netherlands Circular Hotspot (TNCH) (2016). The Netherlands Circular Hotspot. Available at: http://www.netherlandscircularhotspot. $\mathrm{nl}(30.10 .2016)$.

Venlo Green Park (2016). Greenport Venlo. Available at: http://www.venlogreenpark.nl (1.11.2016).

World Commission on Environment and Development (WCED) (1987). Our Common Future. Available at: http://www.un-documents. net (30.10.2016).

World Economic Forum (WEF) (2014). Towards the Circular Economy: Accelerating the scale-up across global supply chains. Geneva: WEF.

Wu, L. Dong, S. \& Chen, F. (2010). A study on tourism development model with dynamic mechanism of circular economy. Ecological Economy, 6, 439-446.

Zhang, X. \& Xiao, C. (2015). Research on the Tourism Circular Economy Mode - Mt. Emei Scenic Area. International Journal of Managerial Studies and Research, 3 (6), 91-96.

Cite this article aS: Pattanaro, G., Gente, V. (2017). Circular economy and new ways of doing business in the tourism sector. European Journal of Service Management, 21 (1), 45-50. DOI: 10.18276/ejsm.2017.21-06. 